\title{
Das Bild geraderücken
}

_ „Von der Ergotherapie wissen wir bereits, dass sie [bei ADHS] überhaupt nicht hilft, sie hat keinen Effekt." Das meinte Professor Marcel Romanos, Leiter der Würzburger Uniklinik für Kinder- und Jugendpsychiatrie, in einem Interview in der Main-Post. Das hat mich geärgert. Rückt er doch so die Ergotherapie in ein schlechtes Bild, ohne zu belegen, wie er zu dieser Aussage kommt.

_ In demselben Interview macht sich Professor Romanos für eine multimodale Behandlung von Kindern mit ADHS stark. Die familiäre Situation solle berücksichtigt und die Umwelt mittherapiert werden. Wichtig seien Beratung und Aufklärung. Genau das kann Ergotherapie leisten! Nicht zuletzt mit dem Ergotherapeutischen Trainingsprogramm ETP bei ADHS von Britta Winter. Eine Studie von Bettina Arasin aus dem Jahr 2009 weist sogar darauf hin, dass es auf die Kernsymptomatik bei ADHS wirken kann. Ich atme also tief durch und nehme an, dass dies nicht bis zu Professor Romanos durchgedrungen ist.

- Leider können wir nicht erwarten, dass sich unsere Erfolge von alleine verbreiten. Wir müssen aktiv und professionell unseren Beruf in der Öffentlichkeit vertreten. Das kann in Vorträgen, Artikeln oder Leserbriefen, aber auch im Kleinen geschehen: Wir alle kennen Statements wie „Da wird nur gespielt“ oder „Ergotherapeuten heilen durch Beschäftigung“. Nicht immer können wir in solchen Situationen eine Studie aus dem Ärmel zaubern. Aber wertvoll und wichtig ist es, in diesen Momenten klarzustellen, dass wir mit unseren Klienten Ziele verfolgen, die ausschlaggebend für das Bestehen in der Schule, das Zurechtkommen im häuslichen Umfeld oder das Bewältigen der beruflichen Tätigkeit sind. „Überhaupt nicht helfen“ sieht für mich definitiv anders aus.

Ich wünsche Ihnen ein kühles Köpfchen, Durchhaltevermögen und viel Erfolg beim Bildgeraderücken,

Ihre

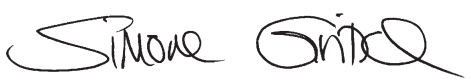

PS: Wer das Interview mit Professor Marcel Romanos nachlesen möchte, findet es unter www.mainpost.de/ueberregional/politik/zeitgeschehen/ ADHS-Unruhe-wegen-eines-Zahlenwerks;art16698,7292304.

ZU GEWINNEN

Kursplatz

1 Kurs Handtherapeut

Seminarbausteine 1-3

Seite 43

Bücher

1x Die große Schule für Djembé \& Dunun mit CD Seite 23

$3 \mathrm{x}$ „Ab jetzt vegan!“ $\quad$ Seite 20

$3 \mathrm{x}$,Tomaten à la rabbiatta"

Seite 18

1x Anatomie und Biomechanik der Hand Seite 43

Und außerdem...

3 CDs „Christian Myer and the mysterious golden Cat on their Journey to Fledermausland“"

Seite 23 